\title{
Gauchers Disease: A Case Report
}

\author{
Dr.Ketan Mhatre ${ }^{1}$, Dr.S Mahore ${ }^{2}$, Dr.K Bothale ${ }^{3}$, Dr.A Patrikar ${ }^{4}$ \\ ${ }^{I}$ Resident, Dept. Of Pathology, NKPSIMS , Nagpur, Maharashtra, India. \\ ${ }^{2}$ Professor And HOD, Dept. Of Pathology, NKPSIMS , Nagpur, Maharashtra, India. \\ ${ }^{3}$ Associate Professor, Dept. Of Pathology, NKPSIMS , Nagpur, Maharashtra, India. \\ ${ }^{4}$ Associate Professor, Dept. Of Pathology, NKPSIMS , Nagpur, Maharashtra, India.
}

\begin{abstract}
Gaucher disease is the commonest lysosomal storage disorder caused due to deficiency of enzyme Glucocerebrosidase. The overall incidence is about 1: 40000. The main clinical features are organ enlargement (liver and spleen), bone marrow infiltration and skeletal involvement leading to bone pain and pathological fractures. Pancytopenia or thrombocytopenia is the commonest clinical presentation secondary to hypersplenismin type I gauchers disease. Enzyme replacement therapy (ERT) has revolutionized the treatment of Gaucher disease. Symptomatic patients of GD 1 and GD 3 merit treatment. ERT is most effective in reducing the liver and spleen size and the bone symptoms, and improving blood counts. This article describes a case of Gauchers disease in a 19 year old female patient.
\end{abstract}

Keywords: Bone marrow infiltration, Gauchers disease, Glucocerebrosidase,Pancytopenia, Lysosomal storage disorder.

\section{Introduction}

Gaucher's disease was first described by Philippe Gaucher in 1882. It is the commonest lysosomal storage disorders and arises as a result of a deficiency of enzyme glucocerebrosidase. The overall incidence is approximately 1:40,000 individuals.Type I Gaucher's disease occurs mainly in adults and is the commonest lysosomal storage disorder . The prevalence of Gaucher's disease is low. Types II and III, which have a variable degree of involvement of the neurologic system, have a very rare incidence, and occur in less than 1:100,000 of the population[1].The main clinical features of adult Gaucher's disease are organ enlargement (liver and spleen), bone marrow infiltration leading to anaemia, thrombocytopenia and leucopenia, and skeletal involvement leading to bone pain and pathological fracture in type 1 gauchers disease[1,2].A case of Gauchers disease in a 19 year old female is presented below.

\section{Case Report}

A 19 yearOld female presented with history of pain and dragging sensation in abdomen since 1 year and weakness with breathlessness since 1 month. Lab investigations revealedCBC :Hb - $8.4 \mathrm{gm} / \mathrm{dl}$, TLC -2500 / cumm ,Platelet count -0.55 lacs / cumm . Clinical diagnosis was hypersplenism with pancytopenia. The patient underwent splenectomy.

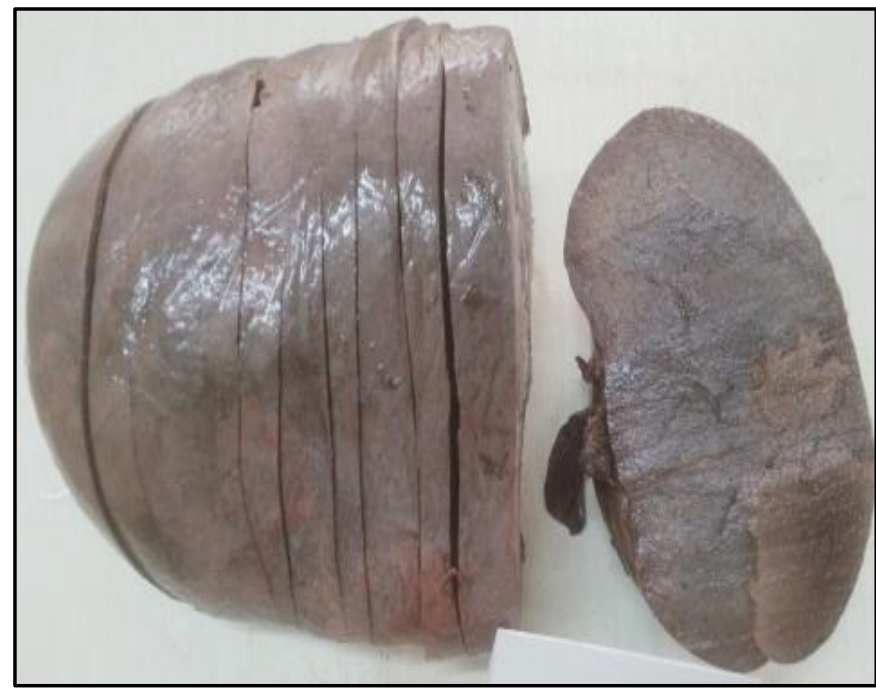

Fig 1 - Gross appearance - Diffusely enlarged spleen weighing $4 \mathrm{~kg}$ and measuring 30 x 20 x $8 \mathrm{~cm}$ 


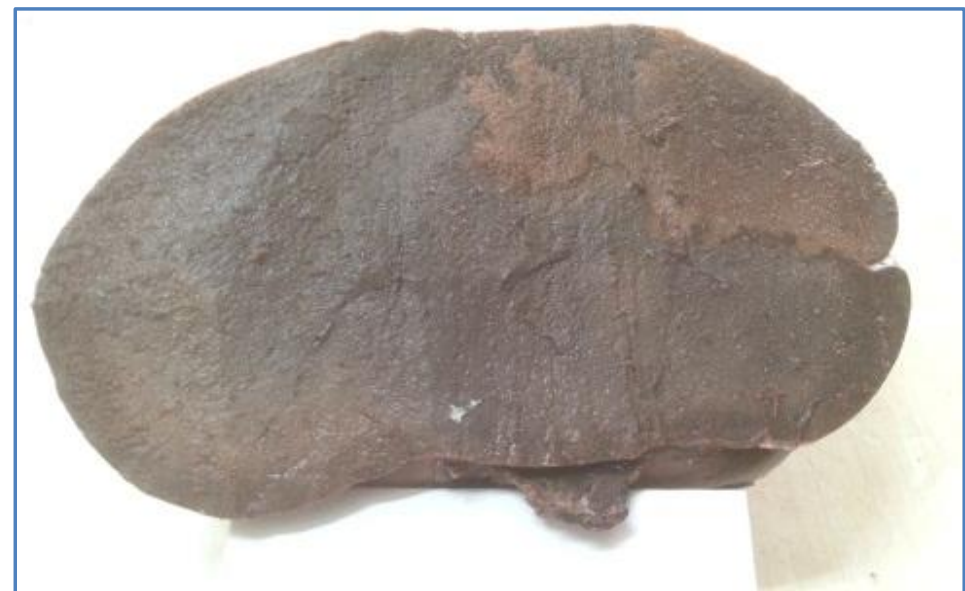

Fig 2 - Cut surface of spleen, greyish brown in colour with a pale area of infarct under the capsule .

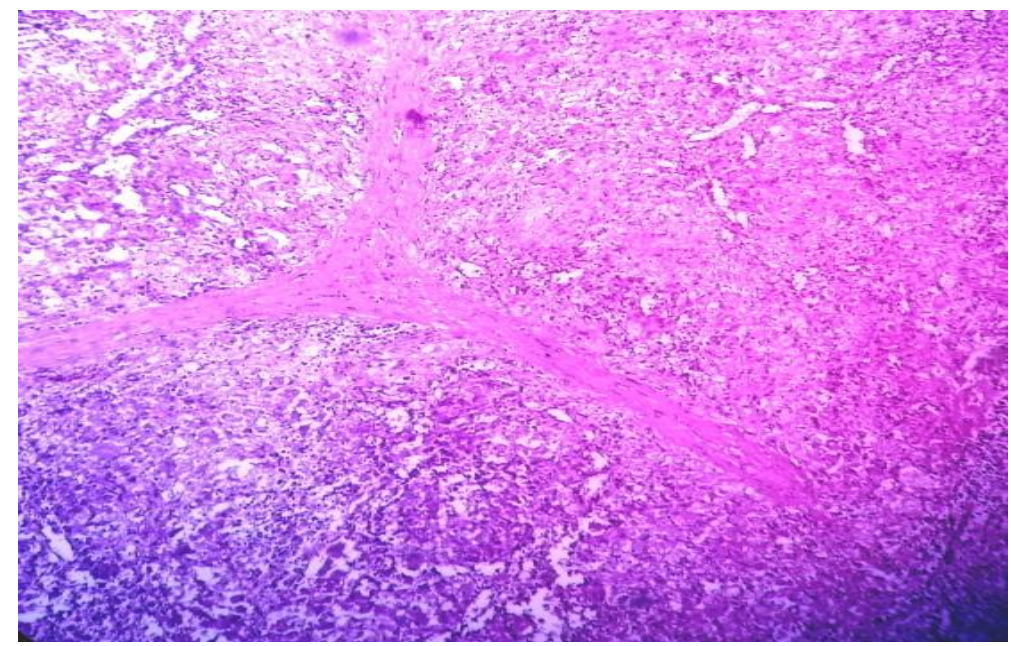

Fig 3 -HP of spleen - Photomicrograph showing effaced spleenic architecture(H \& E,100 x)

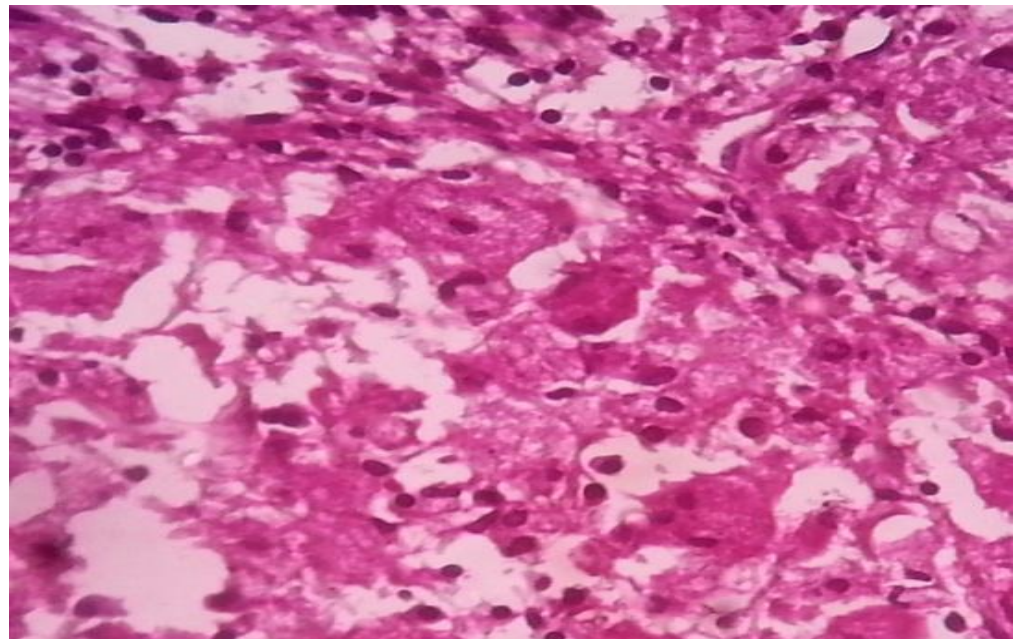

Fig 4- Photomicrograph showing dilated sinuses filled with macrophages with crumpled paper appearance (Gauchers cells)( H \& E ,400x)

\section{Gross}

The spleen was diffusely enlarged weighing $4 \mathrm{~kg}$ and measuring $30 \times 20 \times 8 \mathrm{~cm}$. Cut surface of the spleen was greyish brown in colour with a pale area of infarct undeer the capsule(Fig 1,2) 


\section{Microscopy}

Normal splenic architecture was effaced. Expansion of red pulp was seen. Sinuses were dilated and filled with macrophages with abundant eosinophilicgranular cytoplasm having crumpled paper appearance and central or eccentrically placed nuclei suggesting diagnosis of storage disorder.Final histological findings were consistent with diagnosis of gauchers disease.(Fig 3,4)

\section{Discussion}

Gauchers disease(GD) is the commonest lysosomal storage disease seen in India and world wide.GD results from deficiency of a lysosomal enzyme glucocerebrosidase(also known as acid beta-glucosidase, GBA).Its frequency differs with different populations-being most prevalent- 1:450 birth incidence in individuals of Ashkenazi Jewish descent[3,4].Although GD disease is well known in adult patients but about twothirdsof the patients present before the age of 20 and onset in childhood is predictive of severe and progressive phenotype. The most common signs and symptoms noted in GD are splenomegaly (95\%), hepatomegaly (87\%), radiological bone disease $(81 \%)$, thrombocytopenia $(50 \%)$, anemia $(40 \%)$, growth retardation $(34 \%)$, bone pain $(27 \%)$, and bone crisis $(9 \%)[5]$.

Three types of Gauchers disease have been described based on the clinical features, ethnicity and the natural history of thedisease.Gaucher's disease Type 1 (GD1) occurs mainly in adults and is the commonestlysosomal storage disorder.Gauchers Disease Type II (GD2)and Gauchers disease type III(GD3) patients have onset at less than 1 year, and 2-20 years, respectively.1 GD1 patients do not have neurological involvement. GD2 is the acute neuronopathic and GD3 is the chronic neuronopathic type. GD3 is further subdivided in to 3subtypes $\mathrm{a}, \mathrm{b}$ and $\mathrm{c}$ depending on the clinical features[3,6].

On microscopy, Gaucher cells are positive with PAS, Oil red O, and Prussian blue reaction indicating the nature of accumulated material as glycolipids admixed with haemosiderin[7].

GD I characterised by substrate accumulation which leads to organ damage, principally manifesting as enlargement of the liver, and oftenmassive enlargement of the spleen.Skeletal accumulation of lipid leads to skeletal disease, which in many respects is the hallmark of adult Type I Gaucher's disease. The symptoms of adultGaucher's disease arising as a result of this metabolic defect include bone pain and anaemia leading to tiredness. Bruising and bleeding also occur due to thrombocytopenia, both as a result of bone marrow infiltration and splenomegaly[1].Fatigue, nose bleeds, and easy bruising are a manifestation of the cytopenia[3]. Pathological fractures and bone pain occur if there is extensive expansion of marrow space. Although the disease is progressive in the adult, it is compatible with long life. It is found principally in jews of European stock. Individuals with this disorder have reduced but detectable levels of glucocerebrosidase activity. Longitivity is shortened but not markedly[8].GD 2 is a neuronopathic from of disease with severe neurological disease and is usually fatal by 2 years of age.GD3 is the chronic neuronopathic formof GD and has a later onset than GD2.GD3 is characterized by a milder neurological involvement compared to that seen in GD2, in addition to the visceral and bone marrow involvement as in GD1. Neurologic progression is marked by severe hypertonia, rigidity, arching (opisthotonus), swallowing impairment, and seizures[3].

Glucocerebrosides are continually formed from the catabolism of glycolipids derived mainly from cell membranes of senescent leukocytes and red cells. The pathologic changes in Gaucher disease are caused not just by burden of storage material but also by the activation of macrophages and consequent secretion of cytokines such as IL-1, IL-6, and tumour necrosis factor(TNF)[8]. The diagnosis of GD(homozygotes) relies on demonstration of deficient glucocerebrosidase (glucosylceramidase) enzyme activity in peripheral blood leukocytes or other nucleated cells or in extracts of cultured skin fibroblasts[8,9].Carrier testing by assay of enzyme activity is unreliable because of overlap in enzyme activity between carriers and non-carriers[9]. In principle heterozygotes can be identified by detection of mutations. However, because more than 150 mutations in the glucocerebroside gene can cause gauchers disease currently it is not possible to use a single genetic test. However, with rapid advances in next generation sequencing, it is likely that a comprehensive molecular diagnostic test for carriers will soon be developed[8].The goal of therapy is to reduce the accumulation of the toxic substrate glucocerebroside and other glycolipids to prevent progressive disease with debilitating complications[3].The clinical management of GD has changed considerably over recent decades. Before the availability of Enzyme replacement therapy (ERT) in 1991, management focused on symptom relief (such as splenectomy) for patients with severe disease. With the increased use of ERT over time, symptomatic patients began to receive treatment at younger ages and less severe stages of presentation.ERTremains the gold standard for treatment of gauchersdisease[10].ERT is indicated for patients with type 1 Gauchers disease who manifest with clinical signs and symptoms like anemia, thrombocytopenia, organomegaly and spleenomegaly . Early diagnosis and prompt initiation of treatment when indicated is crucial to prevent or minimize life altering or life threateningliver and skeletal complications[11]. Enzyme replacement therapy seems to eliminate the need for 
bone marrow transplantation and has favourable effects on symptoms and outcome. Development of gene therapy (reintroduction of missing DNA sequence) hints the possibility of real causal therapy of the disease[12].

Substrate (glucocerebroside) depletion through inhibition of glucosylceramide synthase enzyme with oral drugs like Miglustat and Eliglustat tartrate are used for milder disease where treatment with ERT is not possible .These drugs are best used as maintenance therapy after the therapeutic goals have been achieved with ERT Substrate (glucocerebroside).Bone marrow transplantation has the potential for cure of GD.Since the availability of effective ERT bone marrow transplant is no longer the treatment of choice as it has significant morbidityand mortality associated with it. However, when there isno access to expensive ERT, bone marrow transplantation may be an option, albeit inferiorto ERT[3].Early diagnosis and treatment is the best way to prevent further progress of the disease. A multidisciplinary approach and regular followupwill help apatient to lead a better life with less complications. Laboratory facilities for diagnosis and awareness in clinical practice is required to combat the condition[13]. $\beta$-d-glucosidase(GBA) assay in dried blood spots (DBS) represents a method facilitating early identification of patients who will be finally diagnosed with gold standard assay of nucleated cells giving the patients a timely access to therapy[14].

\section{Conclusion}

Gaucher disease is a important cause of pancytopenia. It is the common clinical presentation in type 1 gauchers disease due to hypersplenism. A high index of suspition and early investiations in cases of splenomegaly can lead to early treatment and prevention of complications. GBA assay as a tool for diagnosis/screening will help the patient in early diagnosis and give a timely access to therapy.

\section{References}

[1]. Mehta A, Epidemiology and natural history of Gaucher's disease. European journal of internal medicine, 17, 2006, S2-5.

[2]. Piran S, Roberts A, Patterson MA, Amato D, The clinical course of untreated Gaucher disease in 22 patients over 10 years: hematological and skeletal manifestations, Blood Cells, Molecules, and Diseases, 43(3), 2009, 289-293.

[3]. Nagral A, Gaucher disease, Journal of clinical and experimental hepatology, 4(1), 2014, 37-50.

[4]. Zimran A, Gelbart T, Westwood B, Grabowski GA, Beutler E, High frequency of the Gaucher disease mutation at nucleotide 1226 among Ashkenazi Jews, American journal of human genetics, 49(4), 1991, 855-859.

[5]. Binesh F, Yousefi A, Ordooei M, Bagherinasab MA, Gaucher's Disease, an Unusual Cause of Massive Splenomegaly, a Case Report, Iranian journal of pediatrichematology and oncology, 3(4), 2013, 173-175.

[6]. Levrat V, Forest I, Fouilhoux A, Guffon N, Gaucher disease in childhood, Rev Med Inteme, 28, 2007, $183-186$

[7]. H. Mohan, Genetic and Paediatric Diseases, in Textbook of Pathology, 7 (India: Jaypee Brothers, 2015) 251-260

[8]. V.Kumar, A.k. Abbas, J.C. Aster, Genetic disorders, in Robbins \&Cotran Pathologic Basis of Diseases, 9 (India: Elsevier, 2014) 137-183

[9]. Pastores GM, Hughes DA. Gaucher Disease. GeneReviews. Available at: http://www.ncbi.nlm.nih.gov/books/nbk1269. Accessed November 28, 2016.

[10]. P. Deegan, et al., Blood Cells Mol. Diseases (2016), http://dx.doi.org/10.1016/j.bcmd.2016.10.014

[11]. Nalysnyk L, Rotella P, Simeone JC, Hamed A, Weinreb N, Gaucher disease epidemiology and natural history: a comprehensive review of the literature. Hematology, 2016, 1-9.

[12]. PregunI, Tulassay Z, Gaucher's disease: pathogenesis, diagnosis and therapy, Orv hetil, 145(37), 2004, 1883-1890.

[13]. Bharti RR, Kumar B, Gaucher's Disease: A Rare Case, Diagnosed By Fine Needle Aspiration Cytology. Journal of clinical and diagnostic research, 10(3), 2016, 10(3), ED13.

[14]. Stroppiano M, Calevo MG, Corsolini F, Cassanello M, Cassinerio E, Lanza F, et al, Validity of $\beta$-D-glucosidase activity measured in dried blood samples for detection of potential Gaucher disease patients. Clinical biochemistry, 47(13), $2014,1293-6$. 